\title{
ESR Studies of Copolymerization of Water-Soluble Monomers with Acrylonitrile
}

\author{
Zenzi IzUMI and Bengt RÅnBY \\ Department of Polymer Technology, The Royal Institute \\ of Technology, Stockholm, Sweden.
}

(Received March 29, 1973)

\begin{abstract}
Copolymerization of water-soluble unconjugated monomers $\left(\mathrm{M}_{1}\right)$ with acrylonitrile (AN) has been studied by ESR using a flow system.

The $\mathbf{M}_{1}$-monomers studied were maleic anhydride (MA), sodium allyl sulfonate (SAS), sodium methallyl sulfonate (SMAS), allyl alcohol (AA), sodium vinyl sulfonate (SVS), allyl acetate (AAc), with vinyl acetate (VAc) as reference standard. The initiation reactions and the addition of $\mathrm{AN}$ units to monomer radicals $\left(\mathrm{M}_{1} \cdot\right)$ at $\mathrm{pH} 1.4$ and 7.0 were studied. The addition of small amounts of $A N$ to $M_{1}$ monomers caused a sharp decrease in the concentration of monomer radicals $\left(M_{1} \cdot\right)$, whereas the concentration of allylic monomer radicals (in the cases of AA and SAS), AN. and, especially, the copolymer radicals $M_{1}-A N$. formed from $M_{1}$. increased. The reactivity of sulfonic acid monomer radicals, such as SVS and SMAS, increased almost to double upon changing $\mathrm{pH}$ from 1.4 to 7.0. All results show the very low reactivity of water-soluble unconjugated monomers and their radicals. The $\mathrm{M}_{1}-\mathrm{AN}$. copolymer radicals are characterized by lower $a_{\mathrm{H}}{ }^{\beta}$-values than the AN monomer radical. This is interpreted as due to restricted rotation caused by steric hindrance from the $M_{1}$ units attached to the $\beta$-carbon of the AN radicals.

KEY WORDS Radical Polymerization / Redox Initiation / ESR / Vinyl Sulfonate / Allyl Sulfonate / Methallyl Sulfonate / Allyl Alcohol / Allyl Acetate / Monomer Reactivity / Radical Reactivity / Acrylonitrile / Vinyl Acetate /
\end{abstract}

Previous studies of radical polymerization in our laboratories, using the ESR technique, have dealt with vinyl esters, butadiene, and trimethylolpropane monoallyl ether ${ }^{1-3}$ and copolymerization of vinyl esters with various monomers by Takakura and Rånby. ${ }^{4,5}$ Extensive investigations of transient radicals, mainly of acrylic and methacrylic monomers, initiated with various radical-generating systems, have been reported by Fischer, et al..$^{6-10}$

In all these ESR studies of radical initiation and polymerization in solution, a flow technique first developed by Dixon and Norman ${ }^{11,12}$ has been applied. This technique has proved particularly valuable for the identification of the various transient radicals formed from allyl and methallyl compounds, as recently reported by Izumi and Ranby. ${ }^{13-15}$ ESR studies of copolymerization, as previously described, ${ }^{4,5}$ give data on the reactivity of the monomers and monomer radicals involved. These data are in close agreement with reactivities calculated from $r_{1}$ and $r_{2}$ values obtained from conventional copolymer analysis. The present work is an extension of the ESR copolymerization studies to other groups of monomers.

Although water-soluble unconjugated monomers have become important in industrial applications, their reactions are not well-known, because the low reactivities of these monomers make it difficult to study them by ordinary methods. ESR measurements using the flow method are very useful for studies of the radical species formed and their concentrations and conformations in the midst of the copolymerization process.

Acrylonitrile (AN) was chosen as a common comonomer in the systems studied, because it is water-soluble, highly reactive, and practically important. ${ }^{17,18}$ The monomers $\left(\mathbf{M}_{1}\right)$ studied are 
maleic anhydride (MA), sodium allyl sulfonate (SAS), sodium methallyl sulfonate (SMAS), allyl alcohol (AA), sodium vinyl sulfonate (SVS), and allyl acetate (AAc), plus vinyl acetate (VAc) as a standard reference. For all these copolymerization systems except SAS, well-resolved ESR signals were observed which could be assigned to the initial, transient copolymer radicals $\mathrm{HO}-$ $\mathrm{M}_{1}$-AN.

This paper is mainly concerned with the initiation reaction and the addition of an $\mathrm{AN}$ unit to the monomer radicals formed at $\mathrm{pH} 1.4$ and 7.0. Based on the ESR data, the reactivity of the different monomer radicals to AN monomer was derived and compared with the reactivities calculated from $Q$ and $e$ values. In addition, detailed information on the structure and conformation of the radicals could be derived from the ESR spectra.

\section{EXPERIMENTAL}

The experiments were carried out in a flow apparatus as previously described. ${ }^{1}$ The freeradical spectra were observed during reaction, while the reacting solutions were flowing through a flat quartz cell, $0.25 \mathrm{~mm}$ thick, inserted in a $\mathrm{TE}_{102}$ rectangular resonant cavity of an X-band ESR spectrometer (Japan Electron Optics Laboratory Co., Ltd., Model JES-3B). The polymerization was initiated with hydroxyl radicals formed in a redox reaction between hydrogen peroxide $(0.22 \mathrm{~mol} / l)$ in one solution and titanium trichloride $(0.016 \mathrm{~mol} / l)$ in the other. The $\mathrm{pH}$ of the two solutions was adjusted to 1.4 with $\mathrm{H}_{2} \mathrm{SO}_{4}$ or to 7.0 with EDTA and phosphate buffer. The two solutions were passed with a gravity feed at a combined flow rate of $4.0 \mathrm{ml} / \mathrm{sec}$., giving a time lag from mixing to measurements of about $0.15 \mathrm{sec}$. The ESR measurements were made at room temperature $\left(22 \pm 2^{\circ} \mathrm{C}\right)$ with the first derivatives of the ESR signal recorded. The magnetic field was calibrated with signals of proton magnetic resonance. The concentration of radicals was taken as proportional to the height times the square of the width of the first-derivative curves of the signal.

The following reagents, all of analytical grade, were used in these experiments: $15-\%$ titanium trichloride in water, $30-\%$ hydrogen peroxide in water, concentrated sulfuric acid, ethylene diamine tetraacetic acid (EDTA), sodium hydroxide, potassium dihydrogen phosphate, and disodium hydrogen phosphate. The monomers were of the purest grades commercially available: AN, VAc, and MA (Kebo AB, Sweden), SAS and SMAS (Wako Chemicals, Japan), AA (Merck AG, West Germany), SVS (Hoechst AG, West Germany), AAc (Fluka AG, Switzerland). AN, VAc, AA, and AAc were purified by distillation, and SAS and SMAS were purified by recrystallization. The other monomers were used as received without further treatment.

\section{RESULTS AND DISCUSSION}

\section{Single Monomer System}

Among the monomers studied here, MA has previously been investigated by Dixon, et al. ${ }^{12}$ and VAc by Yoshida, et al., ${ }^{1}$ and Takakura, et $a l .{ }^{4}$ Studies of AA, AAc, SMAS, and SAS are being published elsewhere ${ }^{13-15}$ by the present authors. The ESR spectra of SVS and AN are discussed here briefly.

SVS with $\mathrm{Ti}^{3+} / \mathrm{H}_{2} \mathrm{O}_{2}$ at $\mathrm{pH} 1.4$ gives four different radical spectra, as shown in Figure 1. The strongest is a doublet of triplets which is attributed to monomer-head radicals $\left(\mathrm{HO}-\mathrm{CH}_{2}-\right.$ $\dot{\mathrm{C}} \mathrm{H}-\mathrm{SO}_{3} \mathrm{Na}$ ). A similar but weaker spectrum is a doublet of triplets which is attributed to monomer-tail radicals $\left(\mathrm{CH}_{2}-\mathrm{CH}(\mathrm{OH})-\mathrm{SO}_{3} \mathrm{Na}\right)$. A third and still weaker spectrum is attributed

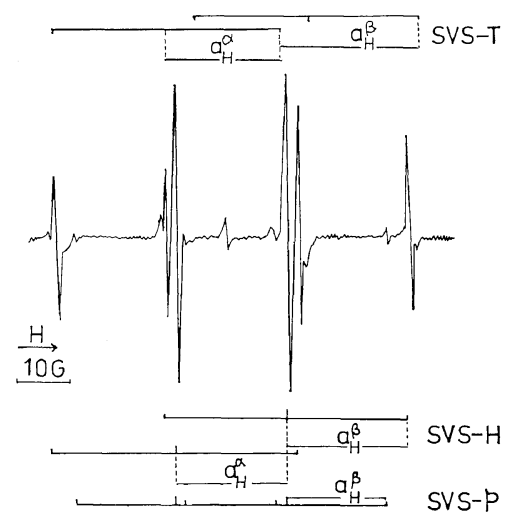

Figure 1. ESR spectrum of sodium vinyl sulfonate (SVS) initiated with $\mathrm{HO} \cdot$ at $\mathrm{pH} 1.4$ and [SVS] $=$ $0.055 \mathrm{~mol} / l$. Spectra of head $(\mathrm{H})$, tail $(\mathrm{T})$, and polymer radicals $(\mathrm{P})$ are indicated. 


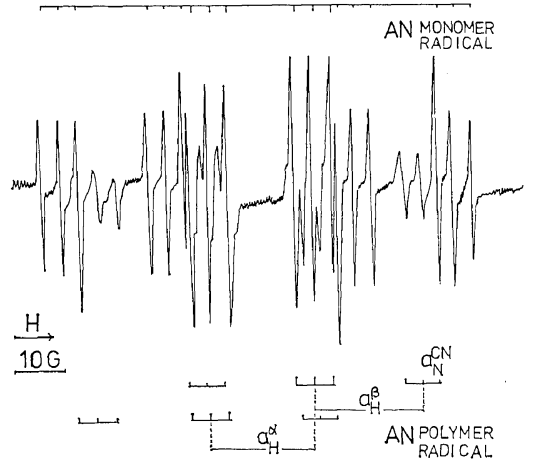

Figure 2. ESR spectrum of acrylonitrile (AN) initiated with $\mathrm{HO}$. at $\mathrm{pH} 1.4$ and $[\mathrm{AN}]=1.0 \mathrm{~mol} / l$.

to polymer-head radicals and is characterized by having smaller coupling constants due to the $\beta$ protons. The fourth spectrum is a singlet which has not yet been assigned. The details of this investigation will be published later. SVS is the only monomer among those treated here giving an ESR spectrum due to polymer radicals at the monomer concentration studied $(0.055 \mathrm{~mol} / l)$.

AN has already been investigated by Fischer, ${ }^{4}$ who obtained no spectrum due to polymer radicals at the monomer concentration $0.114 \mathrm{~mol} / l$. Using a higher monomer concentration $(1 \mathrm{~mol} / \mathrm{l})$, a spectrum due to polymer radicals was obtained, with a $\beta$-coupling constant of $21.07 \mathrm{G}$, as shown in Figure 2.

\section{Binary Monomer Systems}

Series of ESR spectra obtained for the copoly-

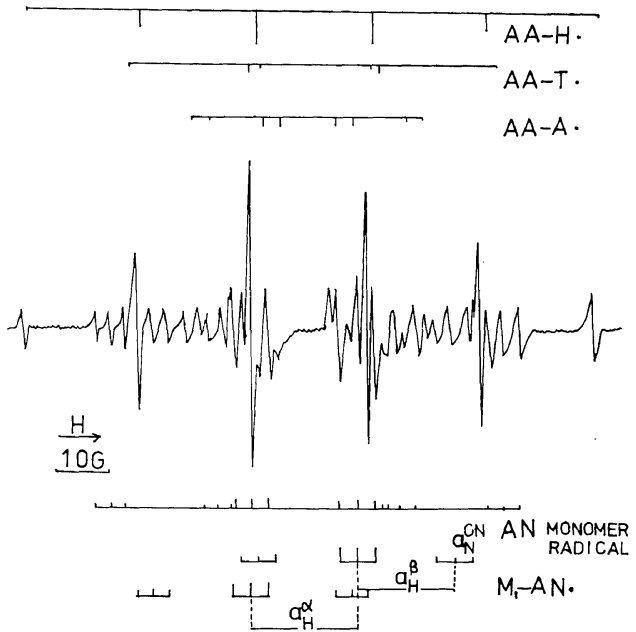

Figure 3. ESR spectrum of a copolymerizing system of allyl alcohol $([\mathrm{AA}]=0.055 \mathrm{~mol} / \mathrm{l})$ and acrylonitrile $([\mathrm{AN}]=0.020 \mathrm{~mol} / l)$, showing head $(\mathrm{H})$, tail $(\mathrm{T})$, and allyl radicals $(\mathrm{A})$ of AA and monomer (AN.) and copolymer radicals (AA-AN.).

merizing systems AA-AN, AAc-AN, SVSAN, SMAS-AN, MA-AN, and SAS-AN were recorded and interpreted. The predominant components of the spectra are well-resolved for each system. Among the many experiments, the results for allyl alcohol will be discussed as an example. A typical ESR spectrum obtained for the polymerization system AA-AN is shown in Figure 3 . In this spectrum five components are resolved.

AA-H. monomer-head radical

( $\mathrm{OH}$ added to the monomer tail)

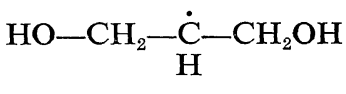

AA-T. monomer-tail radical<smiles>CCC(O)CO</smiles>

AA-A. allylic type radical<smiles>C=CC=CO</smiles>

AN.

AN monomer radical

AA-AN . copolymer radical<smiles>N#C[CH]CO</smiles><smiles>N#CCCC(CO)CO</smiles> 
This interpretation is based on the following facts. The ESR spectrum of pure AA monomer, showing head $(\mathrm{H})$, tail $(\mathrm{T})$, and allyl (A) radicals, was recorded and interpreted in a previous paper. ${ }^{14}$ The AN monomer radical spectrum is shown in Figure 2, obtained at such a high monomer concentration $(1 \mathrm{~mol} / l)$ that polymer radicals of AN appear. At the low AN monomer concentration used in this experiment $([\mathrm{AN}]=0.020$ $\mathrm{mol} / \mathrm{l})$, no AN polymer radical signal is expected to appear in the ESR spectrum. The residual ESR spectral component in Figure 3 is, therefore, assigned to copolymer radicals (AA-AN.) which have a hyperfine structure almost identical with the AN polymer radicals.

In the systems AAc-AN, SVS-AN, SMAS$\mathrm{AN}$, and MA-AN, three types of radical spectra are detected, corresponding to $\mathrm{M}_{1}$. (monomer head radical), AN., and $M_{1}-A N \cdot$. As an example, the ESR spectrum of the system SVS$\mathrm{AN}$ is shown in Figure 4. By comparison with Figure 1 for pure SVS monomer, and Figure 2 for pure AN monomer, it is evident that SVShead radicals $(\mathrm{H})$ and $\mathrm{AN}$ monomer radicals (AN.) are two of the spectral components in Figure 4. In addition, there is a third spectral component which is interpreted to be due to $\mathrm{M}_{1}$-AN. radicals. It resembles the ESR spectrum of AN polymer radicals, (cf. Figure 2) but no polymer radical spectrum of AN is expected at the low [AN] monomer concentration

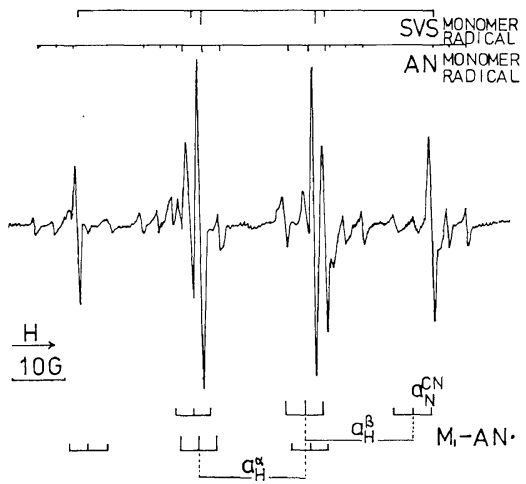

Figute 4. ESR spectrum of a copolymerizing system of sodium vinyl sulfonate ([SVS] $=0.055$ $\mathrm{mol} / l)$ and acrylonitrile $([\mathrm{AN}]=0.020 \mathrm{~mol} / l)$ at $\mathrm{pH}$ 1.4 , showing the two monomer and one copolymer radicals (SVS-AN.).

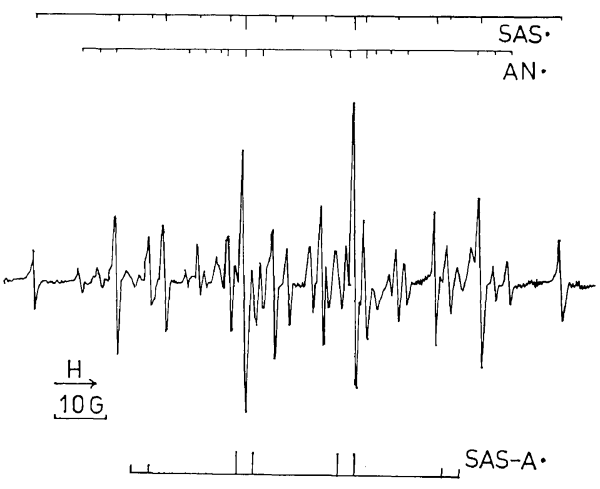

Figure 5. ESR spectrum of a copolymerizing system of sodium allyl sulfonate $((\mathbf{S A S})=0.055$ $\mathrm{mol} / l)$ and acrylonitrile $([\mathrm{AN}]=0.020 \mathrm{~mol} / l)$ at $\mathrm{pH}$ 1.4 , showing the two monomer and one allyl radicals (A) of SAS.

$(0.020 \mathrm{~mol} / l)$ used in Figure 4.

An exceptional case is the system SAS-AN, where monomer radicals of SAS $\left(\mathrm{M}_{1} \cdot\right)$ and AN were found (Figure 5). Instead of copolymer radicals, the allylic-type radicals (SAS-A.) appeared in this case. The allyl radicals could be identified by comparison with the ESR spectrum for pure AA monomer in a previous paper. ${ }^{14}$

The coupling constants derived from the ESR spectra attributed to the initial copolymer radicals $\left(\mathrm{M}_{1}-\mathrm{AN} \cdot\right)$ are summarized in Table I. Data for the monomer radical and polymer radicals of AN and from VAc-AN as a reference, and $Q$ and $e$ values ${ }^{16}$ for the monomers $M_{1}$ are also included in Table I. As seen from this Table, the copolymer radicals $\left(\mathrm{M}_{1}-\mathrm{AN} \cdot\right)$ are characterized by lower $a_{\mathrm{H}}{ }^{\beta}$-values than the corresponding AN monomer radicals. The low $a_{\mathrm{H}}{ }^{\beta}$-values for the copolymer radicals are interpreted as due to restricted rotation caused by steric hindrance from the $M_{1}$ units attached to the $\beta$-carbon of the AN radicals.

\section{Relative Radical Concentrations in the Copolymer Systems}

The relative concentration of the various radical species during copolymerization have been estimated from the intensities of the ESR spectral components. These concentrations are given as a function of AN monomer concentration as shown in Figure 6 for the system AA-AN, in Figure 7 for AAc-AN, in Figure 8 for SVS- 
Table I. Coupling constants of copolymer radicals from $M_{1}-$ AN systems by redox initiation

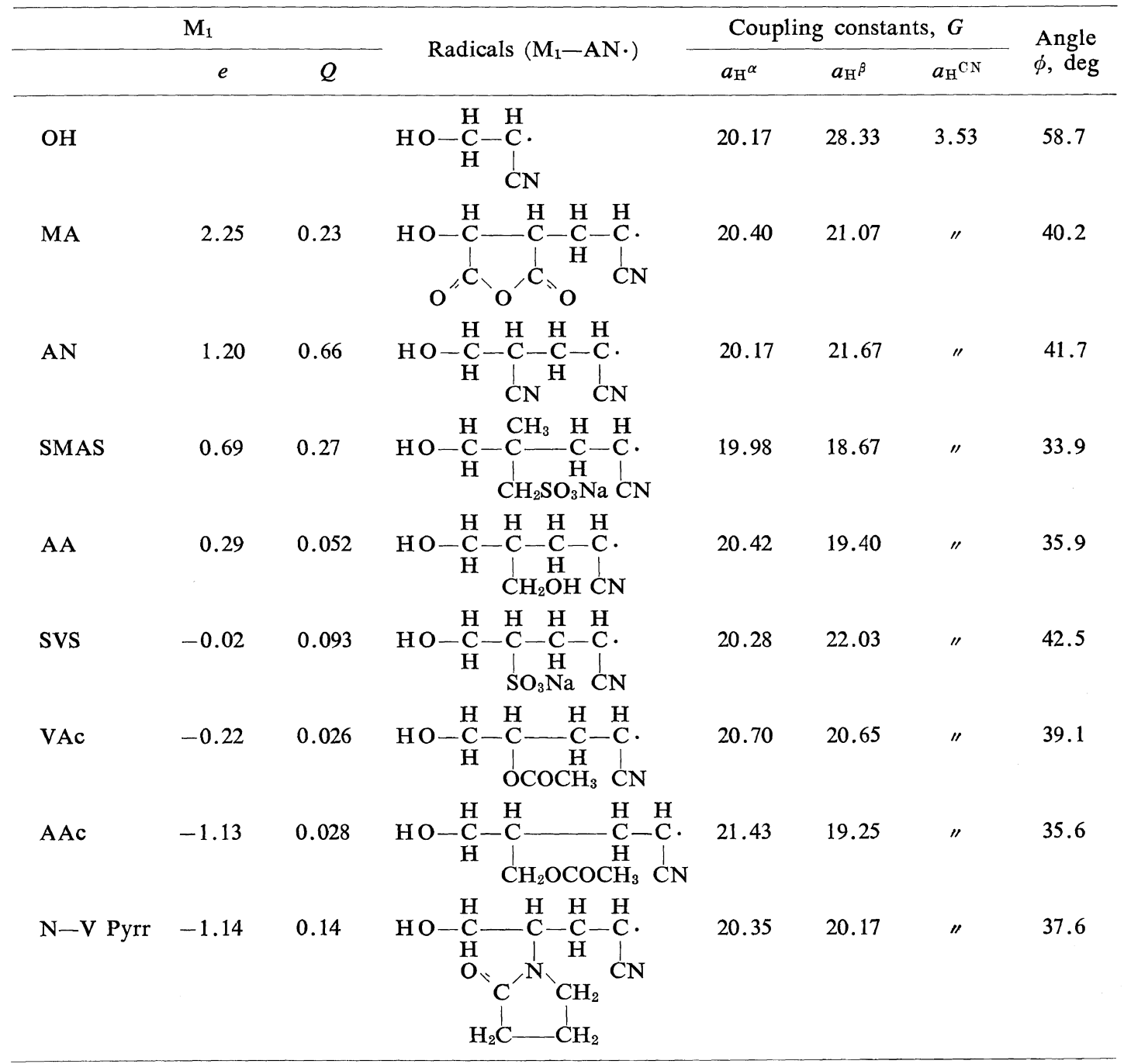

AN, in Figure 9 for SMAS-AN, in Figure 10 for MA-AN and in Figure 11 for SAS-AN. It should be observed that the monomer radical concentration for AA (Figure 6), used as $\left[\mathrm{M}_{1} \cdot\right]$, is the sum of head [AA-H.] and tail [AA-T.] radicals. Both head and tail radicals of AA are found to react with AN monomer. The addition of small amounts of AN caused a sharp decrease in the concentration of $M_{1}$ monomer radical, whereas the concentration of allylic-type radical (in the cases of AA and SAS), AN. and, especially, the copolymer radical $M_{1}-A N$. formed from $M_{1}$. increased. It is interesting to note that we do not get allylic-type radicals in the case of SAS without addition of AN, and we get more allylic-type radicals of AA with increasing AN. This may be due to hydrogen abstraction by $A N$ radicals and to a higher reactivity of AN radicals to allyl hydrogen than of $\mathrm{OH}$ radicals.

For the SVS-AN system, signals due to SVS polymer radicals, which were observed in the absence of AN, were not detected within the AN concentration range studied. This indicates that the addition of AN monomer to SVS monomer radicals is more favored than the addition of 


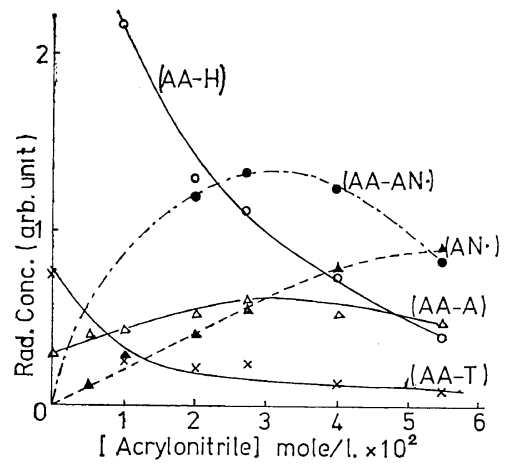

Figure 6. Radical concentrations measured from ESR spectra during copolymerization of AA with $\mathrm{AN}$ at different $\mathrm{AN}$ concentrations in the $\mathrm{AA}-\mathrm{AN}$ system. $[\mathrm{AA}]=0.055 \mathrm{~mol} / l$.

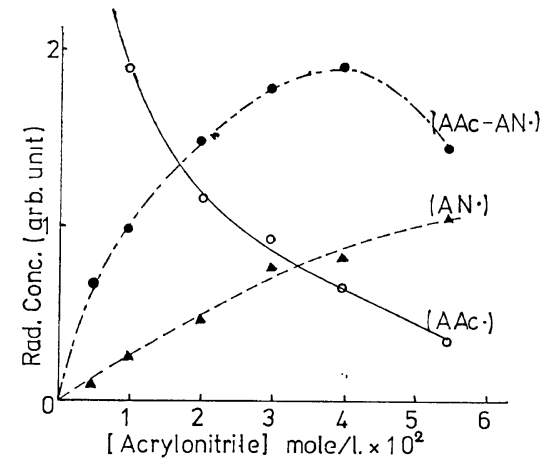

Figure 7. Radical concentrations measured from ESR spectra during copolymerization of AAc with $\mathrm{AN}$ at different AN concentrations in the AAcAN system. [AAc] $=0.055 \mathrm{~mol} / l$.

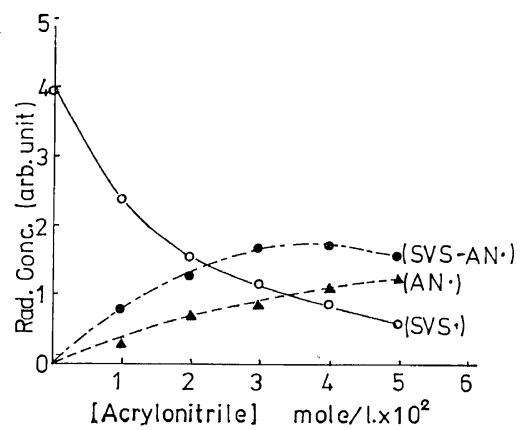

Fignre 8. Radical concentrations measured from ESR spectra during copolymerization of SVS with AN at different AN concentrations in the SVSAN system. $[\mathrm{SVS}]=0.055 \mathrm{~mol} / l$.

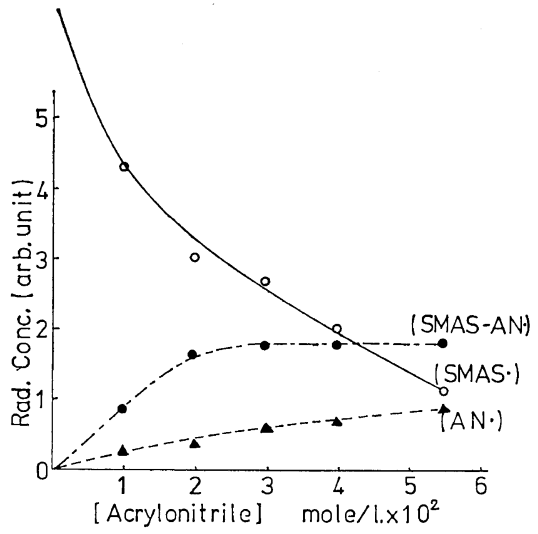

Figure 9. Radical concentrations measured from ESR spectra during copolymerization of SMAS with $A N$ at different AN concentrations in the SMAS-AN system. [SMAS] $=0.055 \mathrm{~mol} / l$.

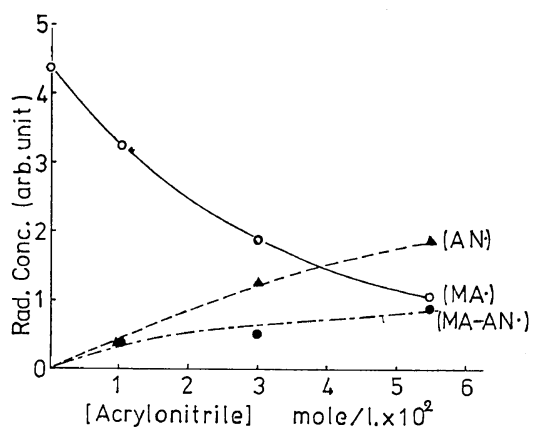

Figure 10. Radical concentrations measured from ESR spectra during copolymerization of MA with $\mathrm{AN}$ at different $\mathrm{AN}$ concentrations in the MA-AN system. [MA] $=0.055 \mathrm{~mol} / l$.

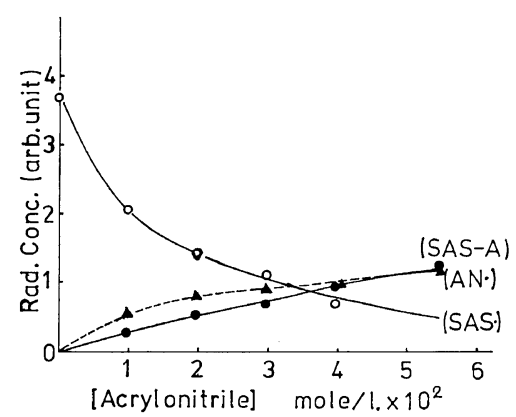

Figure 11. Radical concentrations measured from ESR spectra during copolymerization of SAS with $A N$ at different AN concentrations in the SASAN system. $[\mathrm{SAS}]=0.055 \mathrm{~mol} / l$. 
SVS monomer.

All monomers used as the first components $\left(\mathrm{M}_{1}\right)$ have low reactivity. No ESR signal observed could be attributed to a reverse type of copolymer radical, e.g., AN-AAc. for AAc as $\mathrm{M}_{1}$.

Relative Reactivity of Different Monomer Radicals to $A N$

For a detailed study of the reactivity of the various monomer radicals to AN monomer, the concentration data in Figures 6-11 have been further analyzed. Plots of the concentration ratios $\left[\mathrm{M}_{1}-\mathrm{AN} \cdot\right] /\left[\mathrm{M}_{1} \cdot\right]$ vs. $\mathrm{AN}$ concentration [AN]-a measure of $M_{1}$ radical reactivity-resulted in linear relationships with characteristic slopes, as shown in Figure 12. The different

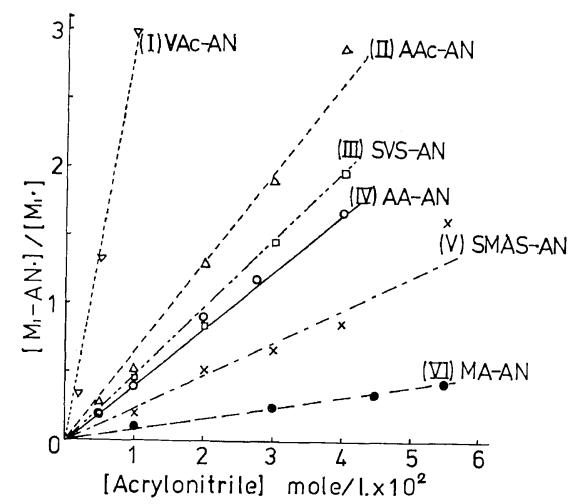

Figure 12. Plots of concentration ratios $\left[\mathrm{M}_{1}-\right.$ $\mathrm{AN}] /\left[\mathrm{M}_{1} \cdot\right]$ vs. concentration of $\mathrm{AN}$ for the systems VAc-AN (I), AAc-AN (II), SVS-AN (III), AA -AN (IV), SMAS-AN (V), and MA-AN (VI); $\left[\mathrm{M}_{1}\right]=0.055 \mathrm{~mol} / \mathrm{l}$.

Table II. The slopes of linear plots of the concentration ratios $\left[\mathrm{M}_{1}-\mathrm{AN} \cdot\right] /\left[\mathrm{M}_{1} \cdot\right]$ vs. $[\mathrm{AN} \cdot]$ and the reciprocal monomer-reactivity-ratios $1 / r_{1}$ calculated from the $Q_{1}$ - and $e_{1}$-values given in the literature

\begin{tabular}{lcccc}
\hline $\begin{array}{c}\text { Copolymer } \\
\text { systems }\end{array}$ & $\begin{array}{l}\text { Slopes } \times 10^{-2} \\
{\left[\mathrm{M}_{1}-\mathrm{AN} \cdot\right] /} \\
{\left[\mathrm{M}_{1} \cdot\right] /[\mathrm{AN}]}\end{array}$ & $1 / r_{1}{ }^{\mathrm{a}}$ & $Q_{1}$ & $e_{1}$ \\
\hline VAc-AN & 3.0 & 31.6 & 0.026 & -0.22 \\
AAc-AN & 0.66 & 30.1 & 0.028 & -1.13 \\
SVS-AN & 0.49 & 8.23 & 0.093 & -0.02 \\
AA-AN & 0.41 & 8.86 & 0.052 & 0.29 \\
SMAS-AN & 0.24 & 1.56 & 0.27 & 0.69 \\
MA-AN & 0.08 & 27.6 & 0.23 & 2.25 \\
\hline
\end{tabular}

a $Q_{2}(\mathrm{AN})=0.60, e_{2}(\mathrm{AN})=1.20$. slopes indicate relative reaction rates of $\mathrm{M}_{1}$. to AN and $M_{1}$ monomer if there is no selective termination with the initiation species $\left(\mathrm{H}_{2} \mathrm{O}_{2}\right.$ or $\mathrm{Ti}^{4+}$ salt). The slopes measured and $1 / r_{1}$-values, calculated from $Q_{1}$ and $e_{1}$ values as given in the literature, ${ }^{14}$ are listed in Table II. With VAc radicals as a reference, the relative rates of conversion of water-soluble unconjugated monomer radicals to $\mathrm{M}_{1}-\mathrm{AN}$ radicals are smaller than those expected from $1 / r_{1}$. This may be related to the reactivities of these radicals, which are much lower than for VAc radicals. Maleic anhydride radicals show an especially low reactivity, due mainly to steric effects. ESR is a convenient method to measure the relative reactivities of various types of transient radicals to one monomer, and no other direct method is known.

Table III. Copolymerization Studies at two $\mathrm{pH}$ values $(1.4 \text { and } 7.0)^{\mathrm{a}}$

\begin{tabular}{llc}
\hline \multirow{2}{*}{$\mathrm{M}_{1}$} & \multicolumn{2}{c}{$\left[\mathrm{M}_{1}-\mathrm{AN} \cdot\right] /\left[\mathrm{M}_{1} \cdot\right]$} \\
\cline { 2 - 3 } & $\mathrm{pH} 1.4$ & $\mathrm{pH} 7.0$ \\
\hline AA & 0.938 & 1.23 \\
AAc & 1.30 & 1.41 \\
SVS & 0.823 & 1.75 \\
SMAS & 0.544 & 1.06 \\
\hline
\end{tabular}

a The reactivities of monomer radicals with AN monomer at different $\mathrm{pH} ;\left[\mathrm{M}_{1}\right]=0.055 \mathrm{~mol} / l$ and $[\mathrm{AN}]=0.020 \mathrm{~mol} / \mathrm{l}$.

Copolymerizations studied at $\mathrm{pH} 7.0$ are listed in Table III and compared with those at $\mathrm{pH}$ 1.4, which is the ordinary condition here. The radical reactivity of sulfonic acid monomers (SVS and SMAS) increases to almost double upon changing the $\mathrm{pH}$ from 1.4 to 7.0 , while the radical reactivity of AAc remains constant. The apparent increase in reactivity of $\mathrm{AA}$ radicals at $\mathrm{pH} 7$ is due to the diminished concentration of AA radicals at high $\mathrm{pH}$, as reported elsewhere. ${ }^{14}$ At $\mathrm{pH} 7$ the sulfonic acid groups are dissociated and the radical becomes an anion, giving the radical an electronegative character. This may increase the reactivity of sulfonic acid radicals to AN monomer, which has a positive character. These tendencies are in accord with the results of the overall copolymerization kinetics. ${ }^{17,18}$ 
Steric Conformation of the Observed Radicals

For aliphatic radicals, the $a_{\mathrm{H}}{ }^{\beta}$-values are known to depend on the steric conformation of the radicals, as given ${ }^{19}$ by the relationship

$$
a_{\mathrm{H}}{ }^{\beta}=\rho \times B_{\mathrm{H}}{ }^{\beta} \times \cos ^{2} \theta
$$

where $\rho$ is the spin density and $\theta$ is the angle between the axis of the $p_{z}$ orbital of the unpaired electron and the direction of the $\mathrm{C}^{\beta}-\mathrm{H}$ bond, projected on a plane perpendicular to the direction of the $\mathrm{C}^{\alpha}-\mathrm{C}^{\beta}$ bond. If the two $\beta$-protons are equivalent, $a_{\mathrm{H}}{ }^{\beta}$ can be calculated ${ }^{7}$ from the equation

$$
a_{\mathrm{H}}^{\beta}=\rho \times B_{\mathrm{H}}{ }^{\beta} \times 1 / 4\left(3-2 \cos ^{2} \phi\right)=\rho \times B_{\mathrm{H}}{ }^{\beta} \overline{\cos ^{2} \theta}
$$

where $\phi$ is the angle between the projection of the $\mathrm{C}^{\beta}-\mathrm{R}$ bond and the axis of the $p_{z}$ orbital, representing the average position of the substituent $\mathbf{R}$ (Figure 13), and $\overline{\cos ^{2} \theta}$ is an average over all angles $\theta$ attained. The most reliable value for $B_{\mathrm{H}}{ }^{\beta}$ to 58.6 gauss. ${ }^{20}$ The $\rho$-value of the copolymer radicals is taken to be 0.785 , and assumed to be the same as the AA monomer radical. ${ }^{7}$ With the use of this relationship, the $\phi$-values for the copolymer radicals were derived from the observed values of $a_{\mathrm{H}}{ }^{\beta}$. They are shown in Table I, from which it can be seen that all the copolymer radicals $\left(\mathrm{M}_{1}-\mathrm{AN} \cdot\right)$ have lower $\phi$-values than the corresponding AN monomer radicals.

This indicates that rotation of the $\mathrm{RCH}_{2}$ group is restricted to a greater extent by the bulky monomer units attached to the $\beta$-carbon atom of the AN units than by the HO groups in the AN monomer radicals. The effects are most

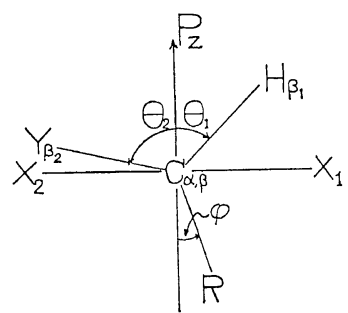

Figure 13. Steric conformation of the free radical of the type $\mathrm{R}-\mathrm{C}_{\beta} \mathrm{H}_{2}-\dot{\mathrm{C}}_{\alpha} \mathrm{X}_{1} \mathrm{X}_{2}$ with the $\mathrm{C}_{\alpha}-\mathrm{C}_{\beta}$ bond perpendicular to the paper plane. pronounced for SMAS, AAc, and AA, which have more bulky side groups than the other comonomers.

Acknowledgment. The authors gratefully acknowledge the financial support for this work by the Swedish Board for Technical Development (STU). Thanks are due to Mr. Pekka Lehmus in this laboratory for helpful discussions and to Mr. James Larsson for reading the manuscript.

\section{REFERENCES}

1. H. Yoshida and B. Rảnby, J. Polym. Sci., Part C, No. 16, 1333 (1967).

2. K. Takakura and B. Rånby, ibid., Part $A-1$, 8, 77 (1970).

3. Y. Doi and B. Rånby, ibid., Part C, 231 (1970).

4. K. Takakura and B. Rånby, ibid., Part B, 5, 83 (1967).

5. K. Takakura and B. Rånby, ibid., Part C, No. 22, 939 (1969).

6. H. Fischer, $Z$. Naturforsch. A, 18, 1142 (1963); ibid. A, 19, 267 (1964); J. Polym. Sci., Part B, 2, 529 (1964).

7. H. Fischer, Z. Naturforsch. A, 19, 886 (1964).

8. C. Corvaja, H. Fischer, and G. Giacometti, Z. Physik. Chem. (Frankfurt), 45, 1 (1965).

9. H. Fischer and G. Giacometti, J. Polym. Sci., Part C, No. 16, 2763 (1967).

10. H. Fischer, Makromol. Chem., 98, 179 (1966).

11. W. T. Dixon and R. O.C. Norman, Nature, 196, 891 (1962); J. Chem. Soc., 3119 (1963).

12. W. T. Dixon, R. O.C. Norman, and A.C. Buley, ibid., 3625 (1963).

13. B. Rånby, J. Macromol. Sci.-Chem., A6, 904 (1972).

14. Z. Izumi and B. Rånby, Pure Appl. Chem., 8, 107 (1973).

15. Z. Izumi and B. Rånby, J. Polym. Sci., in press.

16. G. Z. Ham, "Copolymerization," Interscience, New York, N.Y., 1964.

17. Z. Izumi, H. Kiuchi, and M. Watenabe, $J$. Polym. Sci., Part A, 1, 705 (1963); ibid., Part A, 3, 2965 (1965).

18. Z. Izumi and H. Kitagawa, Kobunshi Kagaku (Chem. High Polymers), 26, 153 (1969).

19. C. Heller and H. M. McConnell, J. Chem. Phys., 32, 1535 (1960).

20. R. W. Fessenden and R. H. Schuler, ibid., 39, 2147 (1963). 